\title{
Evaluation of comparative effectiveness of different insecticides on pediculosis in Wistar rat colony naturally infested by Polyplax spinulosa - A spined rat louse
}

\author{
R. Vigneshwar ${ }^{*}$, K. Imayarasi ${ }^{2}$, S. A. Kumar ${ }^{1}$, R. Pavithra $^{1}$ and J. E. Rani ${ }^{1}$ \\ ${ }^{1}$ Laboratory Animal Facility, Centre for Stem Cell Research, Christian Medical College, Vellore - \\ 632 002, Tamil Nadu, India; ${ }^{2}$ Central Animal Facility, Christian Medical College, Vellore - 632 \\ 004, Tamil Nadu, India
}

\begin{abstract}
Parasitized laboratory animals are not desirable for experiments; hence it is crucial to maintain parasite-free rodent colonies. Though lice infestation is uncommon in laboratory rats, accidental entry into the animal facility may result in pediculosis and causes detrimental effects on the experiments. Since many pre-clinical studies rely on haematological parameters of lab animals, the anaemia caused by pediculosis will alter the study results. In this study, we have reported the morphological characteristics of the spined rat louse Polyplax spinulosa and also evaluated the effect of different ectoparasiticidal agents ( $0.25 \%$ fipronil topical spray; ivermectin injection and oral suspension @ $200 \mu \mathrm{g} / \mathrm{kg} \mathrm{b.wt;} \mathrm{and}$ $\mathbf{0 . 0 5 \%}$ cypermethrin topical spray) on naturally infested Wistar rats. The results showed reduced lice, and eggs count in cypermethrin and ivermectin oral suspension treated groups and complete elimination of lice and eggs in the fipronil and ivermectin injection groups. Though ivermectin subcutaneous injection and fipronil topical spray are effective against the control of $P$. spinulos $a$ infestation, ivermectin lacks ovicidal activity. Hence, two doses of ivermectin injection are required to completely eliminate the infestation. Whereas, fipronil possesses ovicidal activity, a single dose of fipronil treatment is enough to eliminate the louse infestation. This study revealed that $0.25 \%$ fipronil topical spray is effective against the control of $P$. spinulosa infestation in Wistar rats, and its practical administration in large rodent colony is easier than ivermectin injection.
\end{abstract}

Key words: Anaemia, Cypermethrin, Fipronil, Ivermectin, Topical spray

\section{Highlights}

- Pediculosis caused pruritus, alopecia and moderate anaemia in rats.

- Fipronil possesses both nymphicidal and ovicidal activities.

- Ivermectin possesses nymphicidal but lacks ovicidal activity.

- Cypermethrin was not effective against eggs viability and hatching.

- Fipronil showed high efficacy against Polyplax spinulosa infestation in rats.

\section{INTRODUCTION}

Polyplax spinulosa is a spined rat louse that is a member of the order Phthiraptera and suborder Anoplura. P. spinulosa is the common louse of wild rats and is uncommon in laboratory rats. However, accidental entry into the animal facility may occur through wild rodent admittance or a breach in strict bioexclusion measures. It mainly occurs in the fur of the back, shoulders, and neck regions of the host. The female louse lays eggs, known as nits, on hair follicles near the skin of the host; that hatch in 5-6 days (Baker, 2006). The young lice are known as nymphs, they become adults after three molts, and it takes 1-3 weeks of time depending on environmental conditions. The entire life-cycle takes place on the body fur of the host and is completed in 25 weeks. Adults survive only 25-28 days. The mode of transmission between animals is by direct contact (Durden, 2019).

$P$. spinulosa is wide spread in many parts

*Corresponding Author, E Mail: dr.viki91@gmail.com 
of the world. Although infestation rates were once high, improved husbandry practices like autoclaving of the cages and bedding materials, housing the animals in the individually ventilated cages, use of personal protective equipment and disinfectants, and strict bioexclusion measures have significantly reduced the incidence of pediculosis in specific pathogen-free (SPF) animal facilities. However still the incidence may happen in conventional animal facilities. Unlike other ectoparasites, $P$. spinulosa tend to be more host-specific and complete their life cycle in a single host and so are less likely to be found on other hosts or in the environment (Jena et al., 2017; Wang et al., 2018).

Among rats, Wistar rats are commonly used in pre-clinical toxicology studies. Haematologic values are essential diagnostic tools for assessing the health and disease status of the animal related to haematologic disorders, infectious diseases, immune system dysfunction and metabolism, hormone regulation, and organ function. Anaemia caused by pediculosis will alter these parameters resulting in deviation in the study results. Hence, it is necessary to include this ectoparasite in a regular health monitoring program of laboratory animals (Delwatta et al., 2018; Vigneshwar et al., 2021a).

Previous research on this louse primarily focused on the identification, taxonomic classification, and antigenic characterization (Volf et al., 1990; Volf, 1991; Baker, 2006). Recent studies are focused on the epidemiology, genotyping, and phylogenetic analysis of the louse (Wang et al., 2018; Wang et al., 2020). So far, only one report of P.spinulosa infestation in a single Wistar rat has been published by the Indian authors (Jena et al., 2017), but little has been published about the control measures of lice infestation in laboratory rats (Koyee et al., 2011; Moraes et al., 2018). Understanding the louse's life cycle and transmission pattern is essential to develop effective control methods. Selecting a suitable insecticide that should be effective against all stages of the louse life cycle and easy to administer with the minimal risk-benefit ratio is the basis of the effective parasite control program.

Considering the above points, in the current study, we have reported detailed morphological observations of all the stages of the life cycle, such as nit, nymph, and adult stages of $P$. spinulosa collected from the naturally infested Wistar rat colony. Different formulations of commonly available ectoparasiticidal agents have been selected for the treatment with the following objectives:

1. To compare the efficacy of the different insecticides on all stages of the life cycle of the rat louse $P$. spinulosa.

2. To find out the effective insecticide with no or fewer side effects to treat pediculosis in naturally infested laboratory rats.

3. To compare the route of administration of each insecticide and their limitations.

\section{MATERIALS AND METHODS}

Animals: Wistar rats maintained at the central animal facility of Christian Medical College, Vellore, were group-housed on sterilized bedding material (corn cob, Sparconn Life Sciences, Bangalore, India) in polycarbonate cages in different rooms dedicated for breeding, holding, and experimentation and maintained as per the guidelines of the Committee for the Purpose of Control and Supervision of Experiments on Animals (CPCSEA, India). Rats were provided with autoclaved feed (Sai enterprises, Chennai, India) and purified water. In this conventional facility, the environmental parameters of the animal rooms are maintained in the range of $22-25^{\circ} \mathrm{C}$ of room temperature and $40 \%$ to $70 \%$ of relative humidity and 12:12h light: dark cycle of photoperiod.

Case history: Male rats in the adult stock room were observed to be restless with alopecia, and dermatitis on general examination. Detailed clinical examination of those animals revealed the presence of pruritus and reddish-brown spots like lesions on the skin and hair coat of the shoulder and back regions (Fig. 1A \& Fig. 1B). Some animals also showed reddish dots 
on the face and ventral part of the body. The affected animals showed the symptoms of reduced activity, soiled hair coat, scratching, reduced feed and water intake, absence of grooming behaviour, pale eye, and conjunctival mucous membrane. Upon close observation, silver-coloured nits were found attached to hair shafts by parting the fur in the affected area. Under the magnifying lens, the nits appeared like a string of pearls. Numerous yellow-brown coloured adult moving lice were also present in the affected area (Fig. 1C). The skin over the area was thickened and discoloured (Fig. 1D).

Sample collection and analysis: Animals were anesthetized by oxygen-isoflurane inhalation at the concentration of $4 \%$ of isoflurane at the flow rate of 1 LPM (liter per minute), using a small animal anesthetic vaporizer. The fur was scraped off using a surgical blade; hair particles and lice dropped off were collected and examined under low power for morphological analysis. $0.5 \mathrm{~mL}$ of blood sample was collected in EDTA coated vials from tail vein in all the animals for haematological analysis. Haemoglobin ( $\mathrm{Hb})$, red blood cell (RBC) count, haematocrit (HCT), mean corpuscular haemoglobin $(\mathrm{MCH})$, mean corpuscular haemoglobin concentration (MCHC), and mean corpuscular volume (MCV) were measured by an automated animal blood cell counter (Horiba, ABX Micros ESV60). One drop of blood was collected from the tip of the tail by tail sniffing, and thin blood smears were made on the glass slides, and Giemsa's staining was carried out to detect the presence of blood protozoa.

Parasite identification: Adult lice and fur samples were examined under low power (Olympus BX43F microscopy) and imaged using cellSens Standard software. The detected parasite was identified according to its morphological descriptions and illustration described by Baker (2006) and Jena et al. (2017), and it was also confirmed by a veterinary parasitologist. Peripheral blood smears were examined under oil immersion (100X) to rule out the presence of blood protozoa if any.

Treatment protocol: After confirmation of the lice infestation, the affected rats were randomly divided into five groups of eight animals each, constituting the treatment as presented in Table 1.

Drug administration: Cypermethrin 5\% (CYPERVIN 5\% EC) solution was mixed with water, and obtained the therapeutic concentration of $0.05 \%$, and administered topically over the infested areas of skin by spraying. Fipronil $0.25 \%$ (Tick Free spray) solution was administered topically at the dose rate of $10 \mathrm{mg} / \mathrm{kg}$ b.wt by spraying. Ivermectin $0.08 \%$ (HITEK) oral suspension was mixed with sterile water and administered through oral gavage at the dose rate of $200 \mu \mathrm{g} / \mathrm{kg}$ b.wt. Ivermectin $1 \%$ (Neomec) injection was administered subcutaneously at the dose rate of $200 \mu \mathrm{g} / \mathrm{kg}$. Animals were treated on day 0 and once again on day 7 to avoid reinfestation. The control group did not receive any treatment. Animals were housed in different racks to prevent cross-contamination between cages.

To improve the anaemic condition, rats of all groups were fed with a diet rich in iron (188 mg Fe per kg diet, SAFE Diets, France)

Table 1. Treatment protocol followed in different groups

\begin{tabular}{llll}
\hline Group & Treatment followed & Dose/Concentration & Route of administration \\
\hline T1 & Cypermethrin & $0.05 \%$ & Topical spray \\
T2 & Ivermectin & $200 \mu \mathrm{g} / \mathrm{kg} \mathrm{b} . \mathrm{wt}$ & Oral \\
T3 & Ivermectin & $200 \mu \mathrm{g} / \mathrm{kg} \mathrm{b} . \mathrm{wt}$ & Subcutaneous \\
T4 & Fipronil & $0.25 \%$ & Topical spray \\
T5 & Control & - & No treatment \\
\hline
\end{tabular}


for 30 days. Blood samples were collected on day 0 and day 30 to analyse the blood parameters. The efficacy of ectoparasiticides was evaluated by counting the live lice (adults and nymphs) on each animal by coat-parting technique with a magnifying lens. Fur samples were collected from each animal from the heavily infested area on day 0 , day 7 , and day 14 , and eggs were counted under low power, and the results were presented as the number of eggs/low power field (LPF).

Statistical analysis: All data are presented as the mean \pm standard error of the mean (SEM). One-way analysis of variance (ANOVA) was used to compare the means. Post-hoc analysis was done by Duncan's multiple range tests by using the SPSS software package. Graphs were constructed using GraphPad Prism software. $\mathrm{P}<0.05$ was considered statistically significant.

\section{RESULTS}

Morphological characteristics: Morphologically, the louse was yellowish-brown in colour, slender in shape, and apterous (wingless), roughly measuring around 0.6-1.5 $\mathrm{mm}$ in length. The head was short, blunt, and rounded with two large five-segmented antennae. The first antennal segment was large. Eyes and ocular points were absent. The body was thicker, and the ventral thoracic plate was large and pentagonal (shield-shaped) with sixsided thoracic sternal plates. There were six legs with pointed hook-like claws. The first pair of legs (forelegs) was smaller than the second (middle), and the third (hind) pairs of legs; they have no tibial spurs. The abdomen was elongated and well defined with dorsal, lateral, and ventral plates. On each side of the abdomen, seven small sub-triangular lateral plates, 7 to 13 dorsal plates, and 7 to 10 ventral plates were present. There were no prominent hairy processes laterally, and the abdomen was engorged with blood. The abdominal segments bear two rows of setae, and five paratergal plates with pointed dorsal apical angles were also present. Female lice were larger than males and are characterized by two gonophores in the shape of a ' $\mathrm{W}$ ' at the end of their abdomen, whereas male lice have a pointed end of the abdomen (Fig. 2A \& Fig. 2B). Adult female lice showed the outlines of eggs in the abdomen. Eggs (nits) were elongated and appeared as a bunch of grapes attached to the hair close to the skin measured about $0.5 \mathrm{~mm}$. The operculum was porous and cone-shaped (Fig. 2E \& Fig. 2F). The developing nymphs were paler than the yellow-brown adults but morphologically similar and lacked reproductive organs (Fig. 2C \& Fig. 2D). These characteristics are opined with the findings of Baker (2006), Jena et al. (2017) and Wang et al. (2020). Microscopic examination of peripheral blood smears revealed the absence of blood protozoan diseases.

Haematological analysis: Measured haematological parameters of Wistar rats on days 0 and 30 are given in Tables 2 and 3, respectively. The measured analytes were compared with the normal range of haematological parameters of Wistar rats from literature (Vigneshwar et al.,

Table 2. Mean of measured haematological analytes of Wistar albino rats on day $0(n=40)$

\begin{tabular}{llllll}
\hline Analyte & \multicolumn{1}{c}{$\mathbf{T}_{\mathbf{1}}$} & \multicolumn{1}{c}{$\mathbf{T}_{\mathbf{2}}$} & \multicolumn{1}{c}{$\mathbf{T}_{\mathbf{3}}$} & \multicolumn{1}{c}{$\mathbf{T}_{\mathbf{4}}$} & $\mathbf{T}_{\mathbf{5}}$ \\
\hline $\mathrm{RBC}\left(\times 10^{3} / \mathrm{mm}^{3}\right)$ & $5.97 \pm 0.15$ & $5.77 \pm 0.29$ & $5.72 \pm 0.22$ & $5.71 \pm 0.22$ & $6.13 \pm 0.15$ \\
$\mathrm{Hb}(\mathrm{g} / \mathrm{dL})$ & $8.50 \pm 0.38$ & $8.13 \pm 0.48$ & $8.11 \pm 0.41$ & $8.38 \pm 0.28$ & $8.86 \pm 0.43$ \\
$\mathrm{HCT}(\%)$ & $29.41 \pm 0.63$ & $27.83 \pm 0.94$ & $29.22 \pm 0.69$ & $28.52 \pm 0.79$ & $29.72 \pm 0.50$ \\
$\mathrm{MCV}(\mathrm{fL})$ & $49.31 \pm 0.71$ & $48.58 \pm 1.75$ & $51.68 \pm 2.37$ & $50.19 \pm 1.53$ & $48.63 \pm 1.32$ \\
MCH (pg) & $14.19 \pm 0.37$ & $14.13 \pm 0.51$ & $14.19 \pm 0.47$ & $14.72 \pm 0.35$ & $14.40 \pm 0.46$ \\
MCHC $(\mathrm{g} / \mathrm{dL})$ & $26.82 \pm 0.83$ & $29.18 \pm 1.17$ & $27.71 \pm 1.09$ & $29.48 \pm 0.97$ & $29.78 \pm 1.30$ \\
\hline
\end{tabular}


Table 3. Mean of measured haematological analytes of Wistar albino rats on day $30(n=40)$

\begin{tabular}{llllll}
\hline Analyte & \multicolumn{1}{c}{$\mathbf{T}_{\mathbf{1}}$} & \multicolumn{1}{c}{$\mathbf{T}_{\mathbf{2}}$} & \multicolumn{1}{c}{$\mathbf{T}_{\mathbf{3}}$} & \multicolumn{1}{c}{$\mathbf{T}_{\mathbf{4}}$} & $\mathbf{T}_{\mathbf{5}}$ \\
\hline $\mathrm{RBC}\left(\times 10^{3} / \mathrm{mm}^{3}\right)$ & $6.22 \pm 0.16$ & $6.21 \pm 0.20$ & $6.31 \pm 0.24$ & $6.11 \pm 0.18$ & $5.82 \pm 0.11$ \\
$\mathrm{Hb}(\mathrm{g} / \mathrm{dL})^{*}$ & $11.23 \pm 0.39^{\mathrm{a}}$ & $11.18 \pm 0.48^{\mathrm{a}}$ & $12.03 \pm 0.41^{\mathrm{a}}$ & $11.86 \pm 0.36^{\mathrm{a}}$ & $9.27 \pm 0.38^{\mathrm{b}}$ \\
HCT $(\%)^{*}$ & $35.95 \pm 0.97^{\mathrm{ab}}$ & $37.03 \pm 1.37^{\mathrm{ab}}$ & $37.48 \pm 1.12^{\mathrm{ab}}$ & $36.50 \pm 1.26^{\mathrm{ab}}$ & $33.53 \pm 0.79^{\mathrm{b}}$ \\
MCV (fL) & $58.06 \pm 2.08$ & $59.72 \pm 1.74$ & $59.85 \pm 2.27$ & $59.78 \pm 1.65$ & $57.77 \pm 2.05$ \\
MCH (pg)* & $18.10 \pm 0.51^{\mathrm{bc}}$ & $17.98 \pm 0.41^{\mathrm{bc}}$ & $20.70 \pm 1.99^{\mathrm{a}}$ & $23.23 \pm 1.51^{\mathrm{a}}$ & $15.95 \pm 0.72^{\mathrm{c}}$ \\
MCHC $(\mathrm{g} / \mathrm{dL})$ & $31.23 \pm 0.90$ & $30.27 \pm 0.91$ & $30.66 \pm 1.62$ & $29.13 \pm 3.47$ & $27.85 \pm 1.60$ \\
\hline
\end{tabular}

*Means bearing different superscripts within row differ significantly $(\mathrm{P}<0.05)$

2021b). On day 0 , there were no differences between the groups. The animals showed low levels of haemoglobin, RBC, haematocrit, and $\mathrm{RBC}$ indices (MCV, $\mathrm{MCH}$, and $\mathrm{MCHC}$ ) against the normal values. The mean $\mathrm{Hb}$ level in blood was $8 \mathrm{~g} / \mathrm{dL}$ against a normal value of $13.68 \mathrm{~g} / \mathrm{dL}$ depicting moderate anaemia. On day 30 , all the treatment groups showed increased levels of $\mathrm{Hb}$ and other parameters. Treatment groups showed high levels of $\mathrm{Hb}, \mathrm{HCT}$, and $\mathrm{MCH}$ than in control groups.

Antiparasitic efficacy of insecticides against $P$. spinulosa adult lice: Total lice count on days 0 , and 2, 7, and 14 after treatment is given in Fig. 3. There was no statistical difference between the treatment groups on day 0 . On day 2 , the control group $\left(\mathrm{T}_{5}\right)$ showed higher lice count. There was no significant difference between the ivermectin injection $\left(\mathrm{T}_{3}\right)$ group and fipronil $\left(\mathrm{T}_{4}\right)$ and cypermethrin $\left(\mathrm{T}_{1}\right)$ treated groups, whereas ivermectin oral suspension treated animals $\left(\mathrm{T}_{2}\right)$ showed higher lice count, and the difference was statistically significant. On days 7 and 14, fipronil $\left(\mathrm{T}_{4}\right)$ treated groups showed the complete absence of lice. In contrast, cypermethrin-treated animals $\left(T_{1}\right)$ showed the presence of moderate numbers of lice, and the count was higher than day 2 . Ivermectin injection $\left(\mathrm{T}_{3}\right)$ group showed fewer lice on day 7 , and complete absence of lice on day 14. Ivermectin oral suspension treated animals $\left(\mathrm{T}_{2}\right)$ showed the presence of few numbers of lice on days 7 , and 14 , but it was statistically non-significant when comparing groups $\mathrm{T}_{3}$ and $\mathrm{T}_{4}$. The control group $\left(T_{5}\right)$ showed the same levels of lice throughout the study period.

Antiparasitic efficacy of insecticides against $P$. spinulosa eggs viability and hatching: Eggs count (Nos./LPF) on day 0 and days 2, 7, and 14 after treatment are given in Fig. 4. There was no statistical difference between treatment groups on day 0 and day 2 . On day 7 , there was a reduction in egg numbers in all the treatment groups. Group $\mathrm{T}_{4}$ showed the complete absence of viable eggs. Few hatched and dead nits were present, but they were not counted, whereas group $\mathrm{T}_{3}$ and $\mathrm{T}_{2}$ showed fewer eggs than group $\mathrm{T}_{1}$ and the difference was statistically significant. On day 14 , groups $\mathrm{T}_{3}$ and $\mathrm{T}_{4}$ showed the complete absence of viable eggs, whereas group $T_{1}$ and $T_{2}$ showed the presence of a few numbers of viable, unhatched eggs and they differ significantly.

\section{DISCUSSION}

$P$. spinulosa, is a spined, blood-sucking rat louse that completes its life cycle on the host. Heavy infestation may result in anaemia, restlessness, and irritation. The continuous blood spoliation induces the release of histamine, an inflammatory mediator, which results in pruritus. It may affect the health and well being of animals and also alter the study results in experimental animals. In addition, the rat louse may serve as a vector of blood parasites, Mycoplasma haemomuris, Rickettsia typhi, Trypanosoma lewisi, and Borrelia duttoni (Baker, 2006; Greenacre, 2017; Durden, 2019). In our study, the animals showed all the symptoms of lousiness, but they were free from 
Indian Journal of Animal Health, December, 2021

Control of Polyplax spinulosa louse infestation in Wistar rats

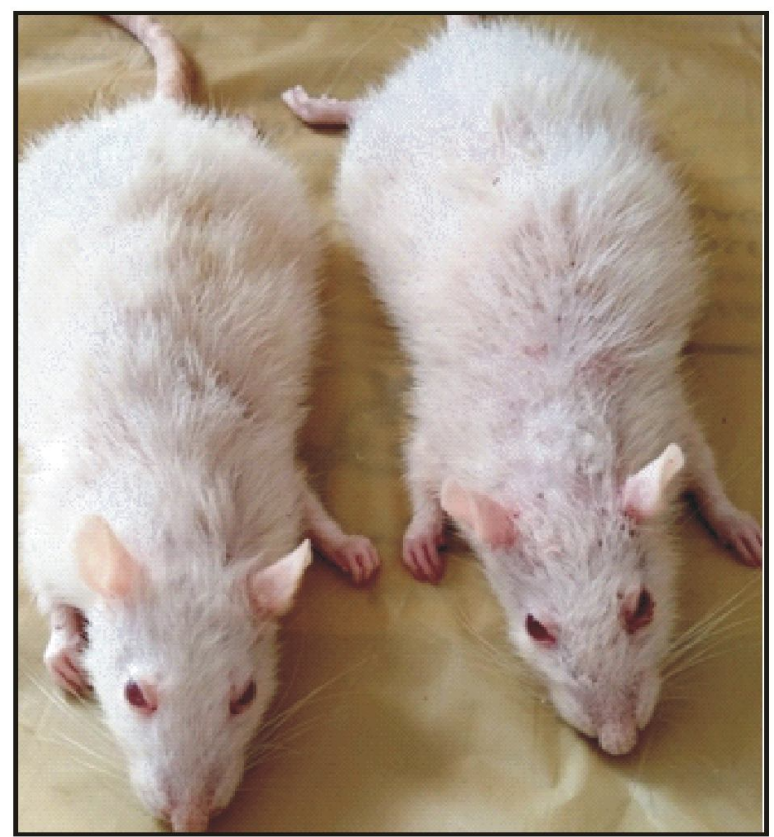

1A. Severely infested animals showing alopecia and 'red dots' like lesions

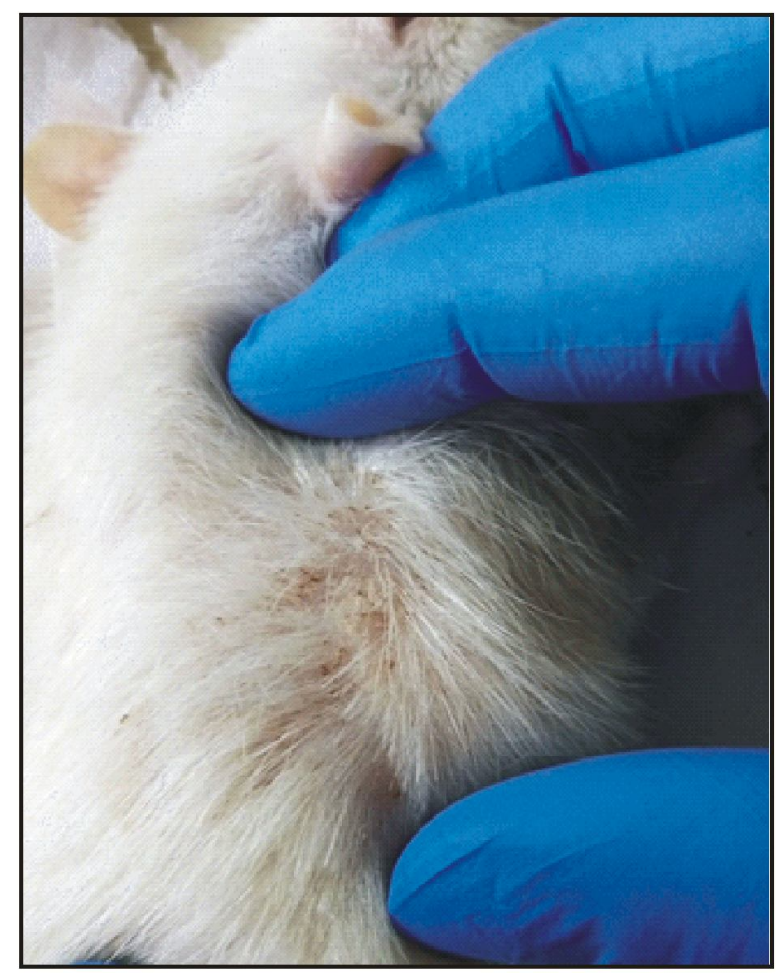

1C. Affected rat showing rough soiled hair coat and presence of yellowbrown colored lice

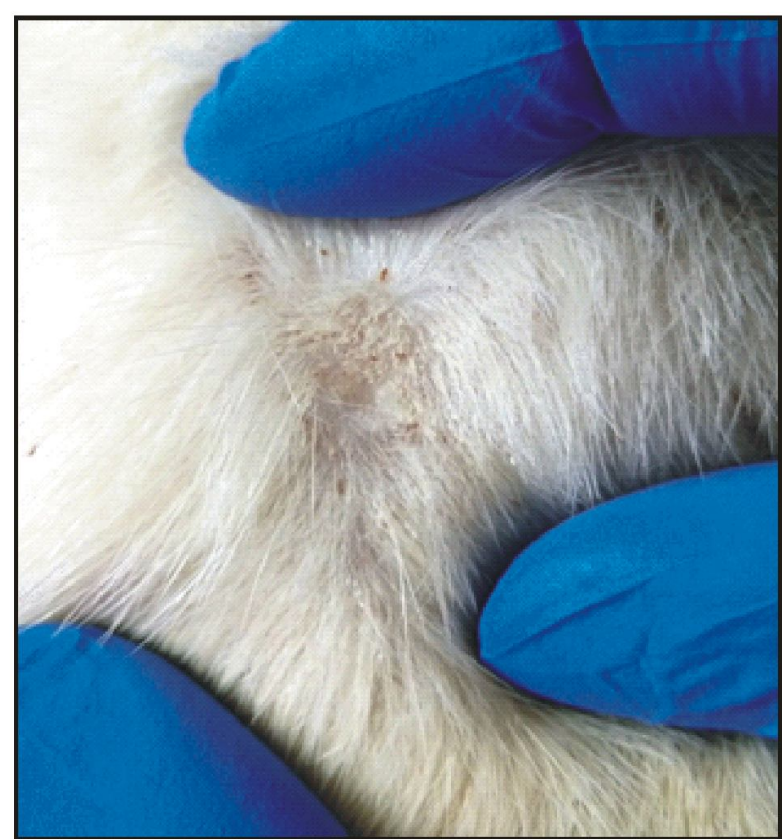

1B. Affected area of skin showing pruritus and presence of nits

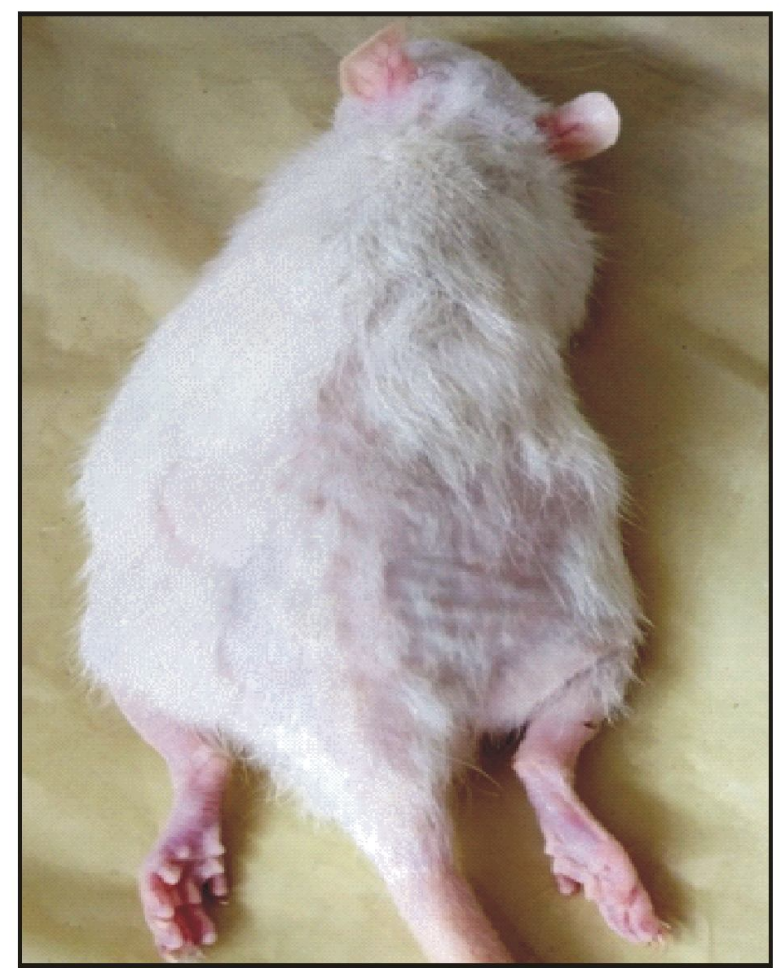

1D. Severe alopecia and dermatitis on the hind quarters of the body

Fig. 1. Clinical signs of pediculosis in Wistar rats 
Indian Journal of Animal Health, December, 2021

Control of Polyplax spinulosa louse infestation in Wistar rats

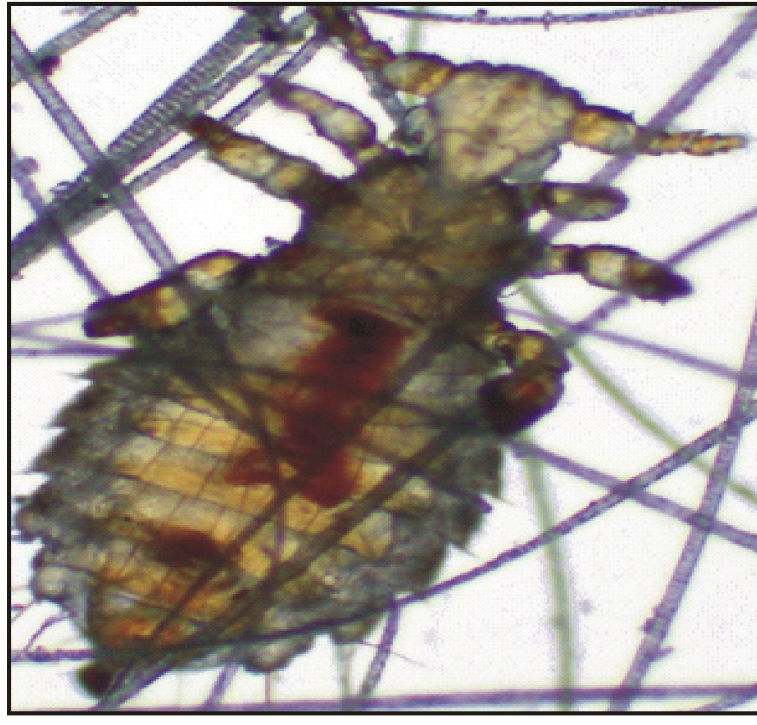

2A. Adult male lice with pointed abdomen

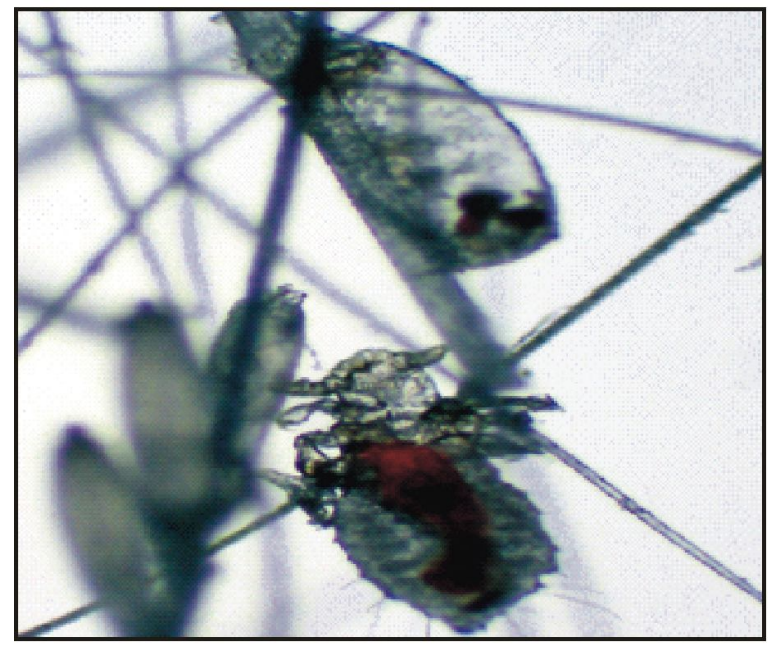

2C. Nymph and ready to hatch egg

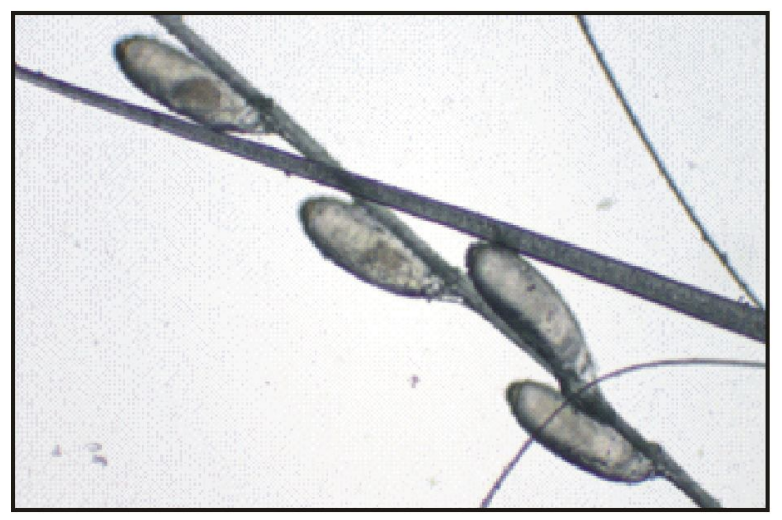

2E. Nits attached to hair shaft

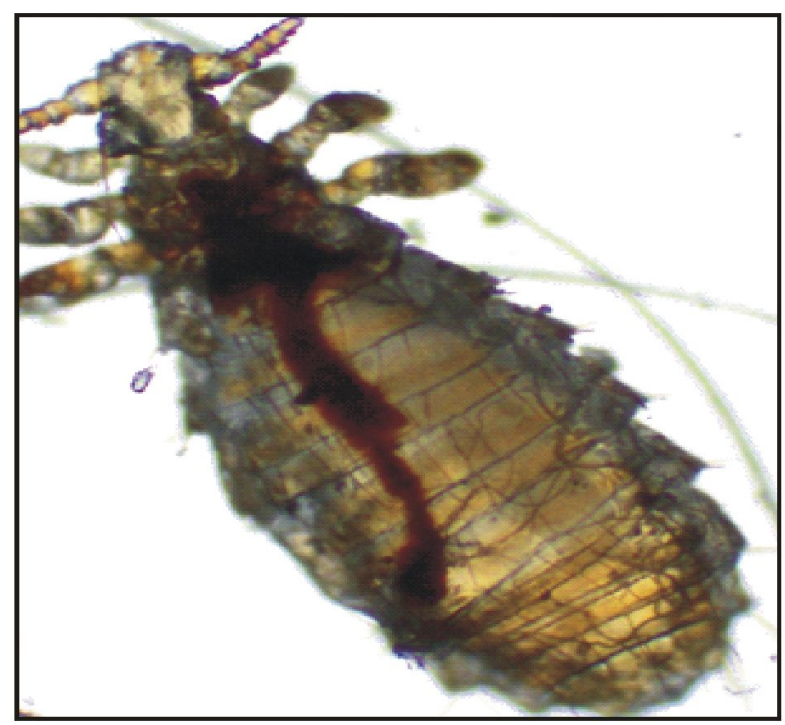

2B. Adult female lice showing ' $W$ ' shaped gonadopores

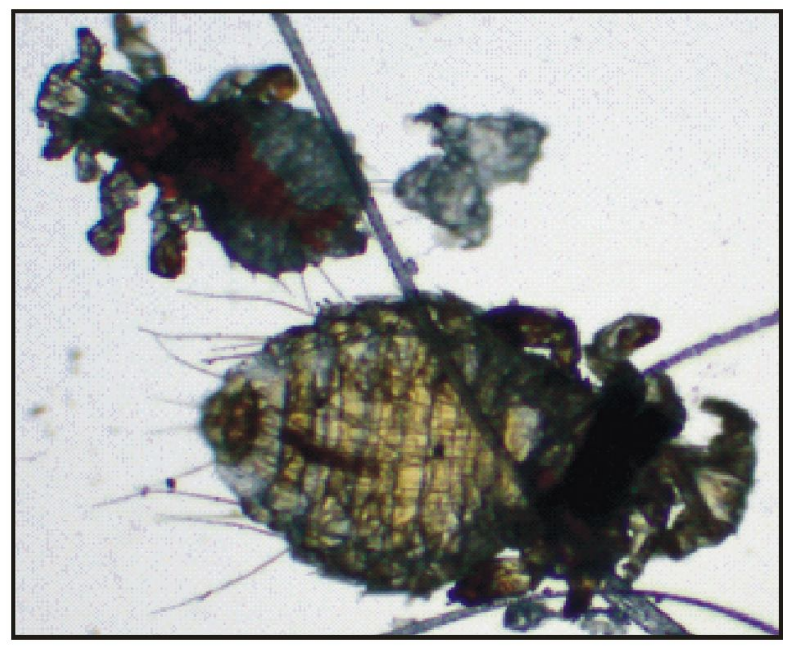

2D. Nymphs of different stages

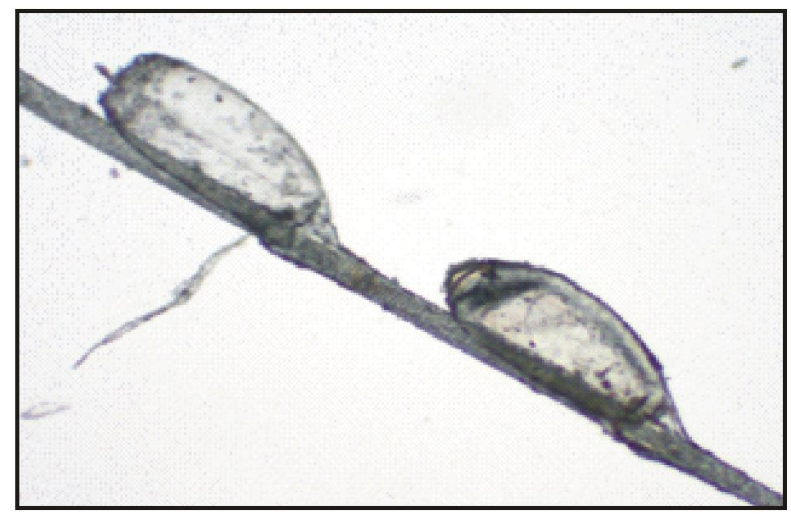

2F. Hatched and unhatched eggs (nits) 


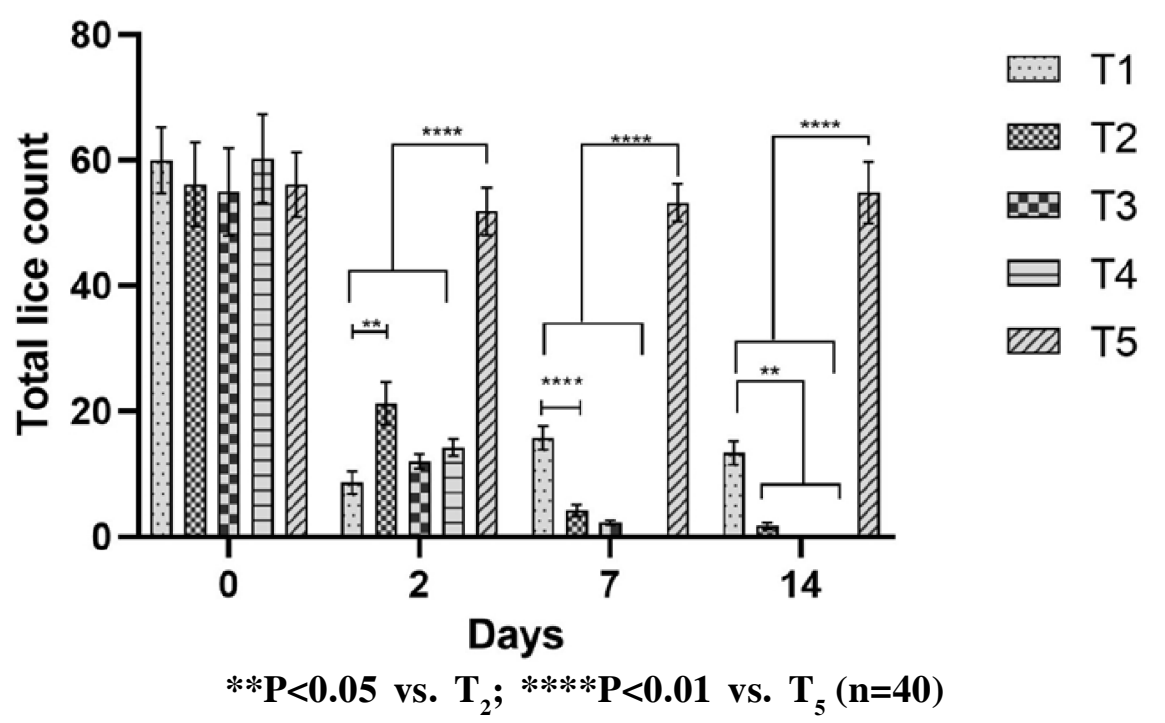

Fig. 3. Total lice count of Wistar rats subjected to different treatments

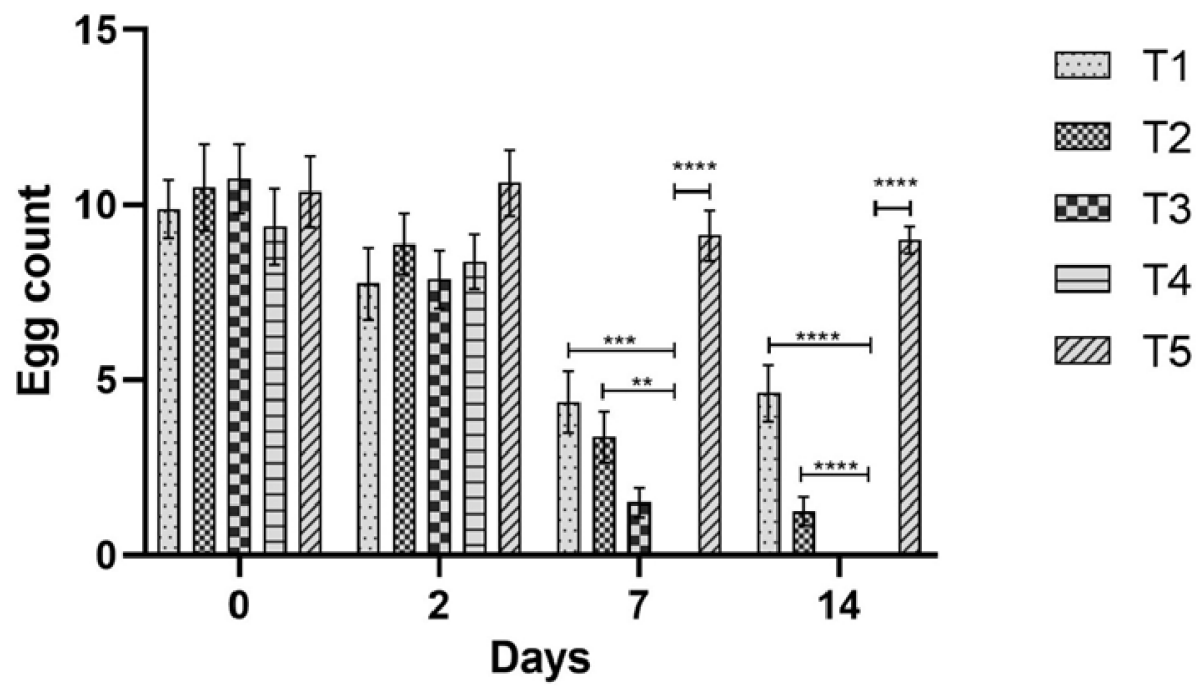

$* * * \mathbf{P}<0.05$ vs. $\mathbf{T} 4 ; * * * * \mathbf{P}<0.01$ vs. $\mathbf{T}_{5}(\mathbf{n}=\mathbf{4 0})$

Fig. 4. Lice eggs count (Nos./LPF) of Wistar rats subjected to different treatments

blood parasites. Our observations are opined with the findings of Jena et al. (2017).

The degree and duration of $P$. spinulosa infestation depend on the strain, age, sex, and genetic factors of the host. Chronic infestation usually induces the production of antibodies against lice antigen, which diminishes louse burdens in the future by gaining partial immunity (Volf et al., 1990). Serum antibody level is directly proportional to the severity and duration of the lousiness. Though the serum antibodies have no direct negative effect on lice, the rats become partially resistant after chronic infestation (Volf, 1991; Volf, 1994). For the first time in our animal facility, we noticed this lice infestation in the rat colony and the treatment was initiated immediately, so we did not analyse the production of serum antibodies against this 
parasite. Isolation and characterization of the lice antigens and host serum antibodies will be the subjects of our future studies in case of reinfestation.

Transmission of $P$. spinulosa is by direct contact. Though the high barrier SPF animal facilities eliminate the parasitic infestation, it may still happen in conventional facilities due to breaches in the bioexclusion measures or wild rodent admittance (Jena et al., 2017). A few weeks prior to this infestation, we noticed the entry of wild rat into our facility through the defect in the exhaust point of the air handling unit (AHU). The wild rat was caught immediately by using a rodent bait station, and the problem in the AHU was corrected. The transmission of the louse might have happened through wild rat entry.

Sucking louse feeds on animal blood, and chronic blood spoliation can lead to blood loss with resultant iron deficiency anaemia. Although there is no relationship between lice infestation and iron deficiency anaemia has been explained, the concurrent presence of these two disease conditions has been reported in cattle, as well as in humans (Shemanchuk et al., 1960; Otter et al., 2003; Burke and Mir, 2011; Althomali et al., 2015) and it is considered as a theoretic possibility (Guss et al., 2011). In our study, the affected animals showed a mean haemoglobin value of $8 \mathrm{~g} / \mathrm{dL}$, depicting moderate anaemia. The range of $\mathrm{RBC}$ and other RBC indices were also reduced. After treatment with insecticides and an iron-rich diet for one month, the rats showed increased haemoglobin levels and other RBC indices.

Fipronil is a broad-spectrum insecticide that is effective against lice, fleas, and mites in domestic animals. Fipronil acts by blocking $\gamma$ aminobutyric acid (GABA) receptor and glutamate-gated chloride ( $\mathrm{GluCl}$ ) channels in insect's nerve membranes, which leads to hyperexcitation and death. Fipronil is very selective in its action because the GABA receptor isoforms are different in animals than in insects, and mammals lack $\mathrm{GluCl}$ channels, which is an invertebrate-specific member of the
Cys-loop family of ligand-gated ion channels present in the neuron and myocytes of an insect (Zhao et al., 2003; Magalhães et al., 2018). These features offer a degree of selectivity, which is highly preferable. When applied topically, it accumulates in the lipid structure of the epidermis, achieving significant concentration in sebaceous glands and hair follicles of treated animals, and continues to be released slowly over a period of time, resulting in a long-residual activity (Diaz, 2005). Fipronil is metabolized to active metabolite fipronil sulphone, which is responsible for prolonged activity. The elimination half-life of fipronil is 7-8 hours, whereas fipronil sulphone is 7-8 days (Hainzl et al., 1998).

Cochet et al. (1997) studied the pharmacokinetics of radiolabeled fipronil $\left({ }^{14} \mathrm{C}\right)$ in beagle $\operatorname{dogs}$ and reported that the radioactivity was mainly seen in the stratum corneum, epidermis, and sebaceous glands but not in the dermal or hypodermal layers, indicating the low percutaneous absorption of fipronil. Since fipronil is not absorbed, it does not produce any systemic toxicity. Fipronil possesses both larvicidal and ovicidal activities; hence, it kills the adult lice and the nymphs and nits of the louse. This point is of great interest in the complete elimination of lice infestation with no side effects in rodent colonies (Diaz, 2005). In our study, the fipronil-treated animals showed complete elimination of adult lice, nymphs, and eggs seven days after the first treatment. However, we have followed the second dose on day 7 as a safety measure.

Fipronil is found to be safe in recommended dosages. The fact sheet published by the US environmental protection agency (USEPA, 1996) regarding the safety of fipronil suggested that dermal acute $\mathrm{LD}_{50}$ in rats is $>2000 \mathrm{mg} / \mathrm{kg}$. A pump of tick free spray from the $100 \mathrm{~mL}$ bottle contains $1-1.5 \mathrm{~mL}$ of the product and 2.5 to $3.75 \mathrm{mg}$ of fipronil, which is very far from the $\mathrm{LD}_{50}$. In our study, fipronil did not cause any adverse effects on the treated animals. Diaz (2005) reported that only two rats out of 125 treated with fipronil suffered mild eye irritation 
due to contact with the spray during administration and the irritation got better within a day. We have properly restrained the animals and covered the eyes during drug administration. According to the results obtained in the present study, fipronil is found to be effective against the control of $P$. spinulosa at the dose rate of $10 \mathrm{mg} / \mathrm{kg}$ b.wt as a single dose without any side effects. This is opined with the findings of Diaz (2005).

Ivermectin is commonly used in veterinary practice for the treatment of ecto and endoparasites. It acts through 3 different mechanisms: 1. glutamate-gated chloride $(\mathrm{GluCl})$ channels mediated hyperpolarization, 2. GABA gated chloride channels mediated blocking of electrical activity, 3. GABA receptor-mediated hyperpolarization of the parasite. Though ivermectin is considered very safe in animals, there are reports of toxic effects in specifically sensitive species (e.g., Collie and Australian Shepherd dog breeds) or due to accidental overdose (Sutherland, 1990; Sandhu, 2012). Rats are not found to be allergic to ivermectin, and the therapeutic dose of $200 \mu \mathrm{g} / \mathrm{kg}$ b.wt is found to be very safe in rats. $P$. spinulosa feed on rat blood several times during each day and young lice require a blood meal soon after hatching from the egg. Ivermectin has no ovicidal activity. As it has a half-life of 2-3 days, a single dose does not allow sufficient drug levels in the bloodstream to kill nymphs as they hatch from their nit capsule 5-6 days later. Hence, treatment must be repeated once, 7-10 days after the first dose (Burkhart and Burkhart, 2000). The ivermectin injection group $\left(\mathrm{T}_{3}\right)$ showed complete elimination of lice and eggs only after the second dose.

We did not observe any side effects in both ivermectin injection, and ivermectin oral suspension treated groups. However, ivermectin oral suspension did not produce $100 \%$ effectiveness against the louse. Even after two doses, there were few adult lice and eggs present on the animals. This fact might be due to the pharmacokinetic characteristics of two different dosage forms. Though ivermectin is very safe in rats, the only practical limitation is the proper dose calculation. It is essential to weigh the animal and calculate the dose every time and it will be time-consuming in a large rat colony, and it also requires a skilled person for injection and oral gavage drug administration procedures, whereas the administration of fipronil topical spray is quite easy.

Cypermethrin is a broad spectrum $4^{\text {th }}$ generation synthetic pyrethroid insecticide. It was effective against the control of moving adult lice but not effective against the unhatched eggs resulted in the persistent infestation throughout the study. Detailed pharmacokinetic profile of cypermethrin in rodents is scarce. 3 out of 8 rats showed reddening and skin irritation on the area of administration, and the symptoms got better within three days. This is on par with the findings of Moraes et al. (2018) who used $0.05 \%$ cypermethrin to treat rats naturally infested by $P$. spinulosa and found out that cypermethrin was not effective against eggs viability and hatching which resulted in low efficacy when compared to fipronil.

According to the study results, both fipronil topical spray and ivermectin injection are effective without any side effects in treating lice infestation in rats. Administration of fipronil topical spray is easier than the ivermectin injection and a single dose is enough to eliminate the infestation. After 30 days of the study, the control animals $\left(\mathrm{T}_{5}\right)$ and animals from groups $T_{1}$ and $T_{2}$ were treated with fipronil spray. Rats housed in the other rooms were checked for the presence of ectoparasite, but they were found to be free from infestation. However, as a prophylactic measure, we sprayed fipronil on all the rats as well as the bedding material to prevent infestation. We also dusted the close vicinity of cages and fomites used in the animal facility with 5\% carbaryl dusting powder to avoid the survival of the escaping louse. The mice colony was completely lice-free based on clinical and fur pluck examinations. Moreover, rats are the specific host of $P$. spinulosa; therefore, mice 
were not included in the prophylaxis.

Since parasite-free animals are essential for research, it is necessary to maintain quality animals. The parasite-free animals can be achieved through the following measures:

1. Procuring parasite-free animals from the standard suppliers.

2. Proper quarantine of the newly imported animals.

3. Proper examination of the integumentary system during health monitoring.

4. Exclusion of vermin.

5. Isolation of sick animals and treatment with an effective insecticide.

6. Hygienic management of the animal facility.

This study demonstrated that a single dose of fipronil topical spray is effective against all stages of the rat louse $P$. spinulosa without any adverse effects, while treatment with ivermectin requires two doses since it lacks ovicidal

\section{REFERENCES}

Althomali SA, Alzubaidi LM and Alkhaldi DM, 2015. Severe iron deficiency anaemia associated with heavy lice infestation in a young woman. BMJ Case Rep, 2015: bcr 2015212207, doi: 10.1136/ bcr-2015-212207

Baker DG, 2006. Parasitic diseases. In: The Laboratory Rat, $2^{\text {nd }}$ edn. (Suckow MA, Weisbroth SH and Franklin CL), Elsevier, London(UK), pp 470-478

Burkhart CN and Burkhart CG, 2000. Oral Ivermectin Therapy for Phthiriasis palpebrum. Arch Ophthalmol, 118(1): 134-135

Burke S and Mir P, 2011. Pediculosis causing iron deficiency anaemia in school children. Arch Dis Child, 96(10): 989, doi: 10.1136/archdischild2011-300791

Cochet P, Birkel P, Brornet-Petit M, Bromet N and Weil A, 1997. Skin distribution of fipronil by microautoradiography following topical administration to the Beagle dog. Eur J Drug Metab Pharmacokinet, 22(3): 211-216, doi: 10.1007/ BF03189809

Delwatta SL, Gunatilake M, Baumans V, Seneviratne MD, Dissanyaka MLB et al., 2018. Reference values for selected haematological, biochemical and physiological parameters of Sprague Dawley rats at the Animal House, Faculty of Medicine, University of Colombo, Sri Lanka. Anim Model activity. Cypermethrin spray was not effective against eggs viability and hatching, resulting in reinfestation, and it also causes local skin reactions.

Ethical permission: The study was conducted following ARRIVE guidelines.

Conflict of interest: Authors have no conflict of interest in this study.

Author's contribution: RV: The study was planned and designed; SAK, RP and JER: Helped in sample collection, laboratory analysis and revising the manuscript. KI: Manuscript preparation and data analysis was done.

\section{ACKNOWLEDGEMENTS}

We thank central animal facility and core laboratory staff for their help in sample collection and processing.

Exp Med, 1(4): 250-254, doi: 10.1002/ ame2.12041

Diaz SL, 2005. Efficacy of fipronil in the treatment of pediculosis in laboratory rats. Lab Anim, 39(3): 331-335, doi: 10.1258/0023677054306980

Durden LA, 2019. Lice (Phthiraptera). In: Medical and Veterinary Entomology, $3^{\text {rd }}$ edn. Academic Press, United States, pp 79-90

Greenacre C, 2017. Avian and exotic animal dermatology. In: Small Animal Dermatology, $4^{\text {th }}$ edn. (Hnilica KA and Patterson AP), Saunders publisher, United States, pp 508-574

Guss DA, Koenig M and Castillo EM, 2011. Severe iron deficiency anemia and lice infestation. J Emerg Med, 41(4): 362-365, doi: 10.1016/ j.jemermed.2010.05.030

Hainzl D, Cole LM and Casida JE, 1998. Mechanisms for selective toxicity of fipronil insecticide and its sulfone metabolite and desulfinyl photoproduct. Chem Res Toxicol, 11(12): 15291535, doi: 10.1021/tx980157t

Jena S, Parthasarathy S and Chawla S, 2017. Identification and morphological characterisation of spiny rat louse (Polyplax spinulosa) from a laboratory rat. J Entomol Zool Stud, 5(6): 82-84

Koyee QMK, Ahmed RK, Aziz KK, Ahmed HS and Abdula AH, 2011. Infestation rate with Polyplax 
spinulosa (Burmeister, 1839) among certain laboratory albino rats (Rattus norvegicus) in relation to different washing agents in two Erbil city universities. Zanco J Med Sci, 15(1): 47-52, doi: 10.15218/zjms.2011.0008

Magalhães ZJ, Sandini MT, Udo SMB, Fukushima RA and de Souza-Spinosa H, 2018. Fipronil: uses, pharmacological and toxicological features. Revinter, 11(1): 67-83, doi: 10.22280/ revintervol11ed1.344

Moraes AC, Prado EJR and Belo MAA, 2018. Antiparasitic efficacy of fipronil in Wistar rats naturally infested by Polyplax spinulosa (Burmeister, 1839). Ars Vet, 34(2): 53-59, doi: 10.15361/2175-0106.2018v34n2p53-59

Otter A, Twomey DF, Crawshaw TR and Bates P, 2003. Anaemia and mortality in calves infested with the long-nosed sucking louse (Linognathus vituli). Vet Record, 153(6): 176-179, doi: 10.1136/vr.153.6.176

Sandhu HS, 2012. Ectoparasiticides. In: Essentials of Veterinary Pharmacology and Therapeutics, $2^{\text {nd }}$ edn. Kalyani Publishers, New Delhi, pp 1053-1055

Shemanchuk JA, Haufe WO and Thompson COM, 1960. Anemia in range cattle heavily infested with the short-nosed sucking louse, Haematopinus eurysternus (NITZ) (Anoplura: Haematopinidae). Can J Comp Med Vet Sci, 24(5): 158-161

Sutherland IH, 1990. Veterinary use of ivermectin. Acta Leiden, 59(1-2): 211-216

USEPA, 1996. Fipronil Pesticide Fact Sheet. EPA 737F-96-005. U.S. Environmental Protection Agency, Washington, USA, pp 7

Vigneshwar R, Arivuchelvan A and Mekala P, 2021a. Thyrogenic, hypolipidemic and antioxidant effects of Bacopa monnieri (Brahmi) on experimental hypothyroidism in rats. $\mathbf{J}$
Pharmacogn Phytochem, 10(1): 454-458

Vigneshwar R, Arivuchelvan A, Mekala P and Imayarasi K, 2021b. Sex-specific reference intervals for Wistar albino rats: haematology and clinical biochemistry. Indian J Anim Health, 60(1): 58-65, doi: 10.36062/ijah.60.1.2021.58-65

Volf P, 1991. Polyplax spinulosa infestation and antibody response in various strains of laboratory rats, Folia Parasitol (Praha), 38(4): 355-362

Volf P, 1994. Localization of the major immunogen and other glycoproteins of the louse Polyplax spinulosa. Int J Parasitol, 24(7): 1005-1010, doi: 10.1016/0020-7519(94)90166-X

Volf P, Grubhoffer L and Matha V, 1990. Antigenic characterization of rat louse Polyplax spinulosa. Folia Parasitol (Praha), 37(3): 275-278

Wang W, Durden LA and Shao R, 2020. Rapid host expansion of an introduced parasite, the spiny rat louse Polyplax spinulosa (Psocodea: Phthiraptera: Polyplacidae), among endemic rodents in Australia. Parasites Vectors, 13(83): 1-15, doi: 10.1186/s13071-020-3957-y

Wang W, Weaver HJ, Song F, Durden LA and Shao R, 2018. A new species of sucking louse Hoplopleura villosissima n. sp. (Psocodea: Phthiraptera: Hoplopleuridae) and a new host record of the spiny rat louse Polyplax spinulosa Burmeister, 1839 (Psocodea: Phthiraptera: Polyplacidae) from the long-haired rat Rattus villosissimus Waite (Rodentia: Muridae) in Australia. Parasites Vectors, 11: 476, doi: 10.1186/s13071-018-3037-8

Zhao X, Salgado VL, Yeh JZ and Narahashi T, 2003. Differential actions of fipronil and dieldrin insecticides on GABA-gated chloride channels in cockroach neurons. J Pharmacol Exp Ther, 306(3): 914-924, doi: 10.1124/jpet.103.051839

Received - 30.10.2021, Accepted - 26.11.2021, Published-01.12.2021

Section Editor: Dr. I. Samanta, Associate Editor 